\title{
'Of Mice and Dementia': A filmed conversation on the use of animals in dementia research
}

\section{Francesco Tamagnini}

University of Reading, School of Pharmacy, Reading, UK

Mark Cotton

Mark Cotton Consultancy, Chair of Kaleider, Exeter, UK

\section{Olwen Goodall}

Head of Internationalisation (retired), Graduate School of Education at University of Exeter, lay member of Exeter University Animal Welfare Ethical Review Board, Exeter, UK

\section{Gillian Harrison}

Alzheimer's Society Research Network Volunteer, UK

\section{Charlie Jeynes}

University of Exeter, Centre for Biomedical Modelling and Analysis, Exeter, UK

\section{Francesca Palombo}

School of Physics and Astronomy, University of Exeter, Exeter, UK

\section{Jean Tomkow and Terry Tomkow}

Alzheimer's Society Research Network Volunteer, UK

\section{Kyle Wedgwood and Jo Welsman}

Centre for Biomedical Modelling and Analysis, University of Exeter, Exeter, UK

\section{Corresponding author:}

Francesco Tamagnini, School of Pharmacy, University of Reading, Reading Hopkins Building, Reading RG6 6LA, UK.

Email: f.tamagnini@reading.ac.uk

\begin{abstract}
Preclinical science research focuses on the study of physiological systems regulating body functions, and how they are dysregulated in disease, in a non-human setting. For example, cells in a dish, computer simulations or animals. Scientific procedures traditionally involve a specialist scientist developing a hypothesis and subsequently testing it using an experimental set-up. The results are then disseminated to the wider scientific community, following peer review and only at the last stage the news will reach the general, lay public. In the last few years, some research funding institutions have promoted a different model, with the direct involvement of members of the public in the research cocreation, from the hypothesis development, to the grant revision, project monitoring and results communication. We personally experienced this model and brought it to a further level by producing a movie. Animal research is a very controversial topic as, while still being necessary for the investigation of body functions, it brings about issues related to the ethics, the regulation and the practical execution of experimental procedures on animals. Here we discuss the different stages of the ideation, production and outcomes of the movie 'Of Mice and Dementia', a filmed conversation on animal experimentation in dementia research. The conversation was between scientists and lay people with a direct experience of dementia.
\end{abstract}

\section{Keywords}

Public patient involvement, Alzheimer's disease, Animal research, Ethics, Laws 


\section{Introduction}

As scientists we have the ability to discover facts, invent things and even create new languages and systems of representation of the World, with the potential to change people's life. For example, in the attempt to cure conditions like Alzheimer's disease (AD) and other forms of dementia. However, this job is being carried out, way more often than it should be, from an ivory tower, representing a position of privilege (which may be due to intellectual excellence), but also of isolation.

The privilege implies a vertical, hierarchical relationship between the expert and the public (with the expert on top), while isolation involves exchange of ideas solely within clustered communities, with low levels of cross communication, not just between experts and the general public, but even between experts in different disciplines.

Living in an ivory tower can give you a nice view of the World, but it can also be counterproductive. Indeed, the lack of communication between experts, stakeholders, policymakers and the general public has the potential to hinder research progress and translation of results that arise from it.

For example, a closed attitude from the experts towards the public can lead to the formation and consolidation of ideas based on false premises. On the other hand, an expert's patronising, hierarchical attitude can lead to the exacerbation and polarisation of public opinions, with results that can be paradoxical (and fun and a bit surreal, like the foundation of the Flat Earth Society), but also dangerous, such as the pseudoscientific idea that the vaccines' safety profile does not counterbalance the benefit they bring to the public health (White, 2014). These phenomena are ever more present in a World in which ideas can spread like wildfire across distant corners of the globe via social media.

A change in the attitude of experts towards a willingness to discuss with, rather than teach, the public may be of key importance for improving both the nature of scientific research conducted and its subsequent impact on society. This could include supporting the development of informed opinions amongst the public, to the generation and implementation of better, fact-based regulations (Brownell \& Roberto, 2015). This is especially true for dementia, an increasing epidemiological problem, characterised by a progressively growing social and healthcare cost, requiring a faster turnover of research into clinical practice (World Health Organization, 2015).

Patient and public involvement (PPI) in some disciplines, such as health services research, has now become a largely established practice. Where the research topic is the human experience it is fairly logical to see the value of including those with personal involvement not only as research participants but in its design and delivery. Here we share our experiences, within primarily fundamental science, of working with the public in dementia research.

\section{Approach to public involvement (PI)}

It is increasingly recognised that biomedical research needs to be informed by the experiences, needs and preferences of the intended beneficiaries of that research - notably those directly affected by the condition. Indeed the National Institute of Health and the National Institute for Health Research expect PPI in the projects it funds; charitable organisations such as Alzheimer's Society are well advanced in their commitment to, and practice of, PPI in even their basic science research.

In an interesting parallel to the hierarchical nature of scientific knowledge alluded to above, in probably the most frequently cited conceptualisation of 'citizen participation', Arnstein (1969) described a ladder in which the rungs relate to increasing levels of involvement in decision making. The bottom rung reflects 'manipulation' and citizen power increases through a series of rungs including amongst others, 'consultation', 'partnership' to 'citizen control' at the top. While this has been useful in getting researchers to reflect on how and where they are engaging with and involving the public, this hierarchical representation does not capture the fluid and dynamic nature of public engagement (PE) and involvement with academic research.

Gibson, Britten and Lynch (2012) and Gibson, Welsman and Britten (2017) describe a conceptual framework, based on sociological theory, that recognises that academic understanding of a given topic is not necessarily superior to lay knowledge, just different. 
However, creating a space where different forms of knowledge can be exchanged on equal terms is often represented as a challenge. It is this approach we have followed here through engaging with lay collaborators at the earliest opportunity and including them in meetings and discussions throughout the project. This differs from many attempts to engage a lay audience with scientific research where the content is designed and produced by the academics and only then shared with the public.

\section{Public and patient involvement in research}

In 2015 one of us (FT) was fortunate to be awarded a research Fellowship from Alzheimer's Society. Already from the selection phase, the Alzheimer's Society Research Network volunteers (a group of lay people with a direct experience of $A D$ and dementia), played a very relevant role, working alongside academics in the grant selection panel. However, the full value of the Alzheimer's Society Research Network volunteers input became clear after the first Monitor meeting. This is a meeting, organised on a yearly basis, aimed at reviewing the progress of the project and, more importantly, to ensure that the feedback from Research Network volunteers continues to inform the development of the project and therefore have the strongest impact on the life of people with AD. It was the first time, in FT experience, that preclinical research was directly informed by the 'end-user', so to speak. The interplay between the Alzheimer's Society Research Network volunteers and our groups has been essential to the definition and refinement of both hypotheses and methodologies, as well as impacting the researchers personally. For example, one of the Research Network volunteers is a retired Royal Navy officer and has a strong scientific background: his feedback was invaluable for both making the science more translatable and developing leadership skills of the research team. These skills are often an issue amongst researchers, as the science life usually leads the researcher from mainly focusing on experiments and analysis (in the postdoctoral years) to having to lead a group of people, with little or no formal education on how to manage a project. In addition, we have found, in the Alzheimer's Society Research Network volunteers, new friends and external collaborators. This aspect may appear secondary, but it actually started a virtuous cascade effect, leading from the specific monitoring of FT's science project to the development and realisation of a wider breadth initiative: a movie on the issues of animal research, which is discussed here. This is, in our opinion, a glaring example of unpredicted impact through PPI in research.

\section{Animal use in research: A controversial topic}

Our research is also based on the use of experimental animals. Animal research has sparked many controversies along the years, often based on the perception of it as (1) unnecessary (i.e. other, more translatable models are available to test a hypothesis), (2) not useful (as animal physiology is different from human) and (3) unethical. These points, while valid, may have some shortcomings. For example, (1) alternative non-animal models are available but they do not currently allow us to address scientific questions which require more complex models (e.g. studying the functional and structural properties of neural networks in the brain). In addition, (2) animals are indeed different from humans, biologically, but they are also similar; as a matter of fact, every single species in the biome shares some level of genetic, biochemical, structural and functional similarity with the others. Finally, (3) using animals can be considered unethical, as they cannot consent to scientific procedures being carried out on them (and if they could they probably would not as some of the procedures involve euthanasia). However, from a utilitarian (as described by the philosopher Jeremy Bentham in the 18th century) point of view (Bentham, 1781), the execution of scientific procedures on animals may be considered ethical, for the advantages that they bring to humanity. The controversy on animal rights and scientific research is still open and very far from being solved (Sunstein et al., 2004).

In summary, it is a complex subject, on which no position can be clearly and ultimately defended. So, how do we deal with it? How do we inform legislators and the public about it? How do we regulate it? One possibility could be to get the public and the experts to talk about the issue and see what comes out of such discussions. Better still, talk about it over a cup of tea. 
Our chance to organise a PI event, aimed at promoting a discussion on animal research between scientists and lay people, stemmed from a joint grant application to a Wellcome Trust Institutional Strategic Support Award (WT105618MA): part of the grant application required the organisation of a $\mathrm{PE} / \mathrm{PI}$ event.

In this project, we aimed to scope, organise and produce a filmed discussion between three dementia scientists with different, increasing involvements in animal research (FT, FP, CJ and KW) and lay people with a lived experience of dementia (JT, TT and GH).

\section{Production}

The format we decided to adopt to produce this video was inspired by two main sources:

Plato's symposium and the Christmas episodes of the Italian TV art programme 'Passepartout', created by the art critic Philippe Daverio. The idea was based on a spontaneous conversation but guided by main thematic frames and with a third-party moderation (MC). This would allow complex themes and different points of view to be discussed, and all of this around a table with food and drinks, specifically tea and cakes, to help create a relaxed atmosphere. We involved an equal number of researchers with different experience of using animals in research, and lay members. The three lay members were Alzheimer's Society Research Network volunteers who, through caring for someone with dementia, each had personal experience of dementia (JT, TT and GH). In addition, a member of the University of Exeter Ethical Committee for Animal Welfare also provided input (OG).

We titled the movie 'Of Mice and Dementia', as an evocative homage to Steinbeck's masterpiece, under the recommendation of JW.

\section{Organised spontaneity: Thematic division}

The aim of the production of 'Of Mice and Dementia' was to simulate a spontaneous conversation, with tea and cake, between lay people and scientists on the topic of animal research in dementia. However, spontaneous conversations tend to naturally follow tangents in a way which may make it difficult for a casual viewer to find the conversation entertaining and informative.

For this reason, the movie was filmed into three broad thematic areas: (1) 'The Ethics', where we discuss, from the philosophical and social point of view, the implications and controversies of animal research, (2) 'The Laws' where we discuss the current UK (Animals, Scientific Procedures, Act, 1986) and European (Directive 2010/63/EU) legislation regulating animal research and (3) 'The Practicalities' where we discuss how animal research is done, on a day-to-day basis, from our own experience and knowledge. Within each thematic area, the conversation has been included in the final movie in its entirety, with no edits. Of course, we would break between one theme and the other to get more cake and to refill our cups.

A final section, the 'Extras', included each one of the scientists explaining in detail the kind of experiments they run and what their respective involvement is in animal research.

This is a key section, as it shows how the interplay between different disciplines, such as physiology, cell biology, physics and mathematics, helps to generate the maximum impact for a scientific study and to reduce, refine and replace the usage of animals.

In addition, it shows how, ultimately, in this historical period, the use of animals is still partially necessary to generate primary data which could not be obtained with other, non-animal-based systems, including clinical studies on humans.

While each section is connected to the other, they can be viewed independently.

The viewer can therefore choose to either watch the whole 90 minutes circa marathon, or to focus on each section and/or subsection, without losing important information about the topic.

\section{Outcomes}

The movie has been produced, and the terms of its distribution are currently being discussed with the University of Exeter. 
However, some results following its production have already been generated. In fact, everyone involved in it had the chance to experience a different view on a very complex and controversial topic. The lay audience were exposed to a full account of the ethics and legislation concerning animal research and its practicalities from the point of view of research scientists. This allowed all parties to engage in the discussion and develop a deeper and more profound view on the topic, as it was very well summarised in the final remarks at the end of the video.

However, to assess and eventually measure the impact of the movie on public opinion, 'Of Mice and Dementia' will have to be distributed widely on video sharing platforms.

We all agreed that animal experimentation is currently necessary. However, every effort should be made to reduce and replace the animal models, especially by redefining experimental protocols. This allows the progression through a historical path which, in turn, may eventually lead to the complete substitution of experimental animals with non-animal models.

\section{Conclusions}

We organised, developed and produced a movie exploring the ethical, legislative and practical issues associated with animal research, with a particular focus on dementia research.

This was made possible by two key factors: (1) the involvement of lay people, such as the Alzheimer's Society Research Network volunteers and (2) the requirement of an important funding body such as the Wellcome Trust to include, in a research project, a PE/PI section.

As a consequence, both scientists and lay members of the public had the motivation to invest time and energy into the production of the movie. This, in turn, resulted in a product that will hopefully promote the formation of informed opinions amongst the general public about animal research. This, in turn, may impact the way the legislators will regulate this delicate issue.

There were several challenges during this project, not just on the organisational and budgeting point of view. For example, we are still negotiating with the University of Exeter the terms for the distribution of the movie, as it touches very delicate issues.

On the other hand, science makes sense only if it is communicated and if it allows everybody (or at least as many people as possible) in a community to be aware what research discovers and how it does it. This should not be a one-way process (the researcher does the science and then communicates it to the public, determining the impact). In fact, the feedback coming from the public (and, whenever possible, the patient) has a key role in informing the development of future research, by helping the scientist to better understand the real-life priorities and recommend ways to improve the impact of their work.

\section{Lessons for practice: What worked and what would we recommend to others}

- Ask researchers to be willing to listen and do not approach this as merely an opportunity to communicate about your research. While an expert opinion can aid the generation of an informed opinion by a member of the public, the fresh perspective of a non-specialist can help to inform novel and more effective research approaches

- Think about the balance of numbers - a similar number of researchers and lay volunteers in our case presented an equal level of conversation

- Inviting a single member of the public would not be best practice

- Creating a relaxing and informal approach to public involvement can help facilitate rapport and discussion on both sides

- Engage with necessary levels of the university management, including the media office at an early stage of any project

- Record more than what you are going to use: cutting things out is easier than adding up at a later stage

- After you are done, keep in touch with all those who were involved in the project

\section{Acknowledgements}


- Wellcome Trust for funding the film production

- Alzheimer's Society for funding FT's research work.

\section{Declaration of conflicting interests}

The author(s) declared no potential conflicts of interest with respect to the research, authorship, and/or publication of this article.

\section{Funding}

The author(s) received no financial support for the research, authorship, and/or publication of this article.

\section{References}

Arnstein, S. R. (1969). A ladder of citizen participation. Journal of the American Institute of Planners, 35(4), 216-224.

Bentham, J. (1781). An introduction to the principles of morals and legislation. Kitchener, Ontario: Batoche.

Brownell, K. D., \& Roberto, C. A. (2015). Strategic science with policy impact. The Lancet, 385(9986), 2445-2446.

Gibson, A., Britten, N., \& Lynch, J. (2012). Theoretical directions for an emancipatory concept of patient and public involvement. Health (London), 16(5), 531-547.

Gibson, A., Welsman, J., \& Britten, N. (2017). Evaluating patient and public involvement in health research: From theoretical model to practical workshop. Health Expectations, 20(5), 826-835.

Sunstein, R. W. U. P. C. R. et al. (2004). Animal rights: Current debates and new directions. New York: Oxford University Press.

White, M. D. (2014). Pros, cons, and ethics of HPV vaccine in teens - Why such controversy? Translational Andrology and Urology, 3(4), 429-434.

World Health Organization. (2015). The epidemiology and impact of dementia. Current state and future trends. Retrieved from http://www.who.int/mental_health/neurology/dementia/dementia_thematicbrief_ epidemiology.pdf

Francesco Tamagnini was born in the Republic of San Marino in 1981. He moved to UK in 2009, during his $\mathrm{PhD}$ in neurophysiology. His work aims at clarifying the connection between brain electricity and memory; particularly, their alterations in Alzheimer's disease. He is currently Lecturer in Pharmacology at the University of Reading.

Gillian Harrison cared for her mother at home for eight years before she died with Alzheimer's disease aged 93. She subsequently became a member of the then newly formed Research Network at the Alzheimer's Society, a volunteer role which involves monitoring research projects which have received AS funding from the lay point of view.

Mark Cotton is a business development consultant and founder of Mark Cotton Consultancy. He also works with Devon Community Foundation and is a Social Enterprise Business Adviser for Dartington School for Social Entrepreneurs and Real Ideas Organisation. Finally, he is Chair of Kaleider, an Exeter based arts production studio.

Olwen Goodall is recently retired, but has been involved in education all her working life. She has been a school teacher, worked with young people with behaviour problems, been an educational psychologist and ended up as a university lecturer. She is the lay member on the University of Exeter Animal Welfare Ethical Review Board. 
Charlie Jeynes is a STFC Fellow working at the Centre for Biomedical Modelling and Analysis, University of Exeter, UK. He is a biochemist whose research focuses on developing new bioprobes and microscopy techniques for analysing cells and tissue.

Francesca Palombo's research is focused on the development of Brillouin, Raman and FTIR spectroscopy methods for applications to the biomedical sciences. She is particularly interested in the physical and chemical aspects of biological systems at a molecular level, as well their implications in disease.

Jean Tomkow was drawn into this world of research when her mother received a diagnosis of dementia in 2009. She had no science background but has found it fascinating. Above all she wants to see success in finding ways of supporting people with dementia and, eventually, finding some way of ending this distressing disease.

Terry Tomkow joined the Alzheimer's Society in 2012 after his wife showed him some applications for funding research. His working life has involved teaching to 11-18 year-old pupils in schools, as well as service personnel in the Royal Navy in which he served for 17 years. He was enthralled by the prospect of helping the search for a cure.

Kyle Wedgwood is a mathematician interested in how networks of interacting cells work together to produce a wide range of functional behaviours. He takes data from experimental scientists and constructs mathematical descriptions that try to explain the biological processes that generate different patterns of activity.

Jo Welsman has a background in quantitative research, and more recently she worked in both health services research and engaged research - roles in which she involves members of the public as collaborators in academic research. Jo believes that all conversations around research should include, as equals, the people intended to benefit from it. 